

\title{
Electricity Market Manipulation: How Behavioral Modeling Can Help Market Design
}

Giulia Gallo

National Renewable Energy Laboratory

NREL is a national laboratory of the U.S. Department of Energy Office of Energy Efficiency \& Renewable Energy Operated by the Alliance for Sustainable Energy, LLC

This report is available at no cost from the National Renewable Energy Laboratory (NREL) at www.nrel.gov/publications.

Technical Report

NREL/TP-5D00-65416

December 2015

Contract No. DE-AC36-08GO28308 


\title{
Electricity Market
}

Manipulation: How Behavioral Modeling Can Help Market Design

\author{
Giulia Gallo
}

National Renewable Energy Laboratory

Prepared under Task No. 065D.1404

NREL is a national laboratory of the U.S. Department of Energy Office of Energy Efficiency \& Renewable Energy Operated by the Alliance for Sustainable Energy, LLC

This report is available at no cost from the National Renewable Energy Laboratory (NREL) at www.nrel.gov/publications.

National Renewable Energy Laboratory 15013 Denver West Parkway Golden, CO 80401

303-275-3000 • www.nrel.gov

\section{Technical Report}

NREL/TP-5D00-65416

December 2015

Contract No. DE-AC36-08GO28308 


\title{
NOTICE
}

This report was prepared as an account of work sponsored by an agency of the United States government. Neither the United States government nor any agency thereof, nor any of their employees, makes any warranty, express or implied, or assumes any legal liability or responsibility for the accuracy, completeness, or usefulness of any information, apparatus, product, or process disclosed, or represents that its use would not infringe privately owned rights. Reference herein to any specific commercial product, process, or service by trade name, trademark, manufacturer, or otherwise does not necessarily constitute or imply its endorsement, recommendation, or favoring by the United States government or any agency thereof. The views and opinions of authors expressed herein do not necessarily state or reflect those of the United States government or any agency thereof.

This report is available at no cost from the National Renewable Energy Laboratory (NREL) at www.nrel.gov/publications.

Available electronically at SciTech Connect http:/www.osti.gov/scitech

Available for a processing fee to U.S. Department of Energy and its contractors, in paper, from:

\author{
U.S. Department of Energy \\ Office of Scientific and Technical Information \\ P.O. Box 62 \\ Oak Ridge, TN 37831-0062 \\ OSTI http://www.osti.gov \\ Phone: 865.576.8401 \\ Fax: 865.576.5728 \\ Email: reports@osti.gov
}

Available for sale to the public, in paper, from:

\author{
U.S. Department of Commerce \\ National Technical Information Service \\ 5301 Shawnee Road \\ Alexandria, VA 22312 \\ NTIS http://www.ntis.gov \\ Phone: 800.553 .6847 or 703.605 .6000 \\ Fax: 703.605.6900 \\ Email: orders@ntis.gov
}




\section{Acknowledgments}

Funding for this report was provided by the National Renewable Energy Laboratory's Laboratory Directed Research and Development Director's Fellowship Program.

Thank you to Paul Denholm, Greg Brinkman, Ella Zhou, and Kara Clark for their helpful comments and reviews and to Katie Wensuc for her editing. 


\section{List of Acronyms} ARES

BCR

CAISO

ERCOT

FERC

ISO

JPMVEC

ORDC
Agent-Based framework for Renewable Energy Studies

bid cost recovery

California Independent System Operator

Electric Reliability Council of Texas

Federal Energy Regulatory Commission

independent system operator

JP Morgan Ventures Energy Corp.

operating reserve demand curve 


\section{Table of Contents}

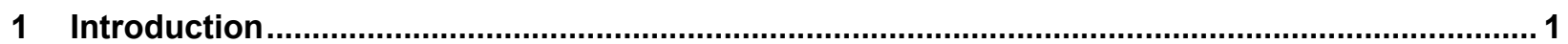

2 Variable Generation and the Gaps in Current Market Design..................................................... 3

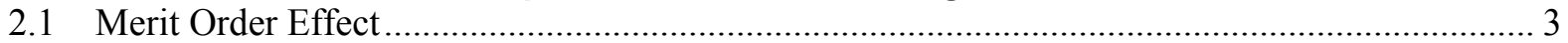

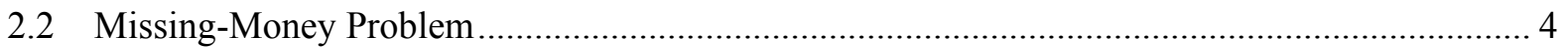

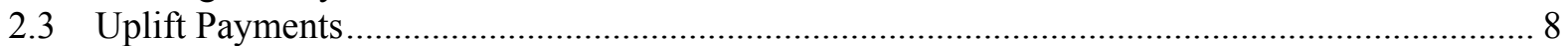

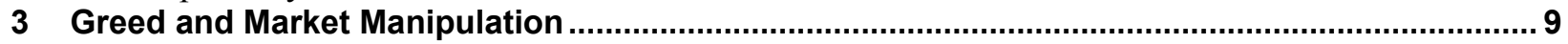

4 Challenges to Modeling Current and Future Electricity Markets ........................................... 12

5 Behavioral and Agent-Based Modeling of Electricity Markets .............................................. 15

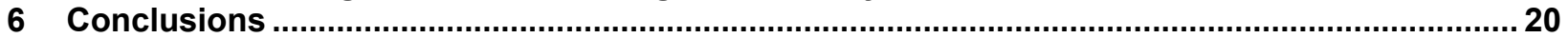

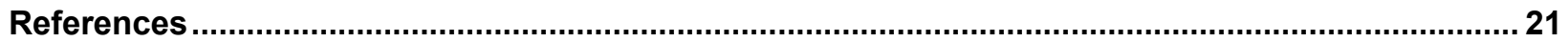




\section{List of Figures}

Figure 1. (Left) Power generation by source in the Nordic region in 2013 and (right) Nord Pool Spot system prices in 2013. Image from Nordic Energy Regulators (2014) ................................... 4

Figure 2. Illustration of the missing-money problem. Image by author ................................................ 5

Figure 3. Prices at the system-wide offer cap in ERCOT. Image from Potomac Economics (2015) ........... 6

Figure 4. Evolution of the ORDC price adders since their introduction in June 2014. Image by author based on calculations derived from publicly available data from ERCOT ............................ 7

Figure 5. Example bids from generation in ERCOT during a yearly period. These histograms show that although most bids are clustered around the operational cost of producing energy, some of the bids are many times larger than the marginal costs. Images by author based on data publicly available from ERCOT...

Figure 6. Example bids from generation in ERCOT during a yearly period. These two graphs show that a generator changed their offer curves in two months, and (left panel) they bid many times larger than their marginal costs. Images by author based on data publicly available from ERCOT

Figure 7. Flowchart of agent-based modeling frameworks. Images from (left) Gallo (2015) and (right) Cincotti and Gallo (2013).....

Figure 8. Price duration curve comparison between the (left) high demand scenario and (right) low demand scenario. Baseline scenario $=\mathrm{B}$, agent-based scenario $=$ A. Images from Gallo (2015)

Figure 9. Distribution of each agent profits within the simulation. Profits have been normalized by each agent total capacity. Baseline scenario = B, Agent-based scenario = A. Image from Gallo (2015)

Figure 10. Fat-tail phenomenon observed in one sample of market prices obtained with ARES. Image from Gallo (2015) 


\section{Introduction}

Electricity market designs govern how market participants generate, sell, buy, and consume electricity and use the electricity infrastructure. The ultimate goal of a well-designed market is to satisfy consumers' demand for electricity at minimum cost by investing in and providing the right quantity and mix of generation resources.

As pointed out by Cramton (2003), good market design should identify critical issues and address them as simply as possible. It is generally accepted that initial attempts to design and model electricity markets had serious flaws because markets were built and designed by committees of stakeholders and via consensus among interested parties. In addition, inadequate attention was paid to the implications of market power and the ability of market participants to manipulate markets. This led to problems in early markets in the California Independent System Operator (CAISO) and ISO New England (Cramton 2003).

Some of the most important and pressing design flaws have been addressed by different entities in the United States. These flaws include the single-settlement methodology, single-part bids, and price discovery mechanisms. With a single-settlement methodology, participants submit bids one day ahead, and changes to their supply schedules can be made until the last minute without penalty. This can lead to the exercise of market power and other market inefficiencies. With only the ability to submit single-part bids, suppliers could bid only increasing supply schedules for each hour without being able to express their true preferences, which are complicated by the technical parameters of the generators. Finally, instead of implementing a locational marginal pricing approach, the early price discovery mechanism used zonal prices, which did not model the presence of binding transmission constraints, and thus it sent the wrong price signals to market participants (Cramton 2003). However, market power and the ability to manipulate markets are pressing topics, and much work has yet to be done.

Moreover, increasingly high shares of renewables are competing with conventional technologies because they are resources that have near-zero variable production costs. For many years, markets have relied on baseload and peak generation to provide flexibility to the grid and reliability during times of scarcity. Market rules and design followed the evolution in the generation mix, and they were able to successfully create designs that have provided proper market signals. However, these markets were not originally designed to consider how they would react and how market outcomes would be affected by high penetrations of renewable generation. Thus, as higher penetrations of renewables were integrated onto the electric grid, market designs and rules did not follow suit as fast as the levels of renewables increased.

Even though economic theory predicted some of the phenomena that is currently experienced today-for example, the missing-money problem (see Section 2.2) it is not clear whether measures to address these issues when they appeared were implemented as by-products to fix problems ex post facto and not ex ante as measures to plan and prepare for expected future scenarios. For example, forthcoming price depressions are expected because of the large amount of renewables setting market prices. This might make it harder to build new generation capacity in regions where outdated coal-powered plants will be retired to adhere to the U.S. 
Environmental Agency's Clean Power Plan. ${ }^{1}$ Additional challenges in planning and operating power systems and new market design flaws that have not yet been addressed could arise. For example, as coal-fueled generators are retired during the next decade, will market design experts be called on to design new markets, draft new pricing rules to guarantee cost recovery, and build new, presumably more efficient power plants? Current market design is flawed and unable to provide the right incentives to build new generation capacity, and new models are needed.

Modeling and designing electricity markets must consider elements such as how supply and demand are created and the decisions that affect the markets at different time frames, including investing in new generation, retiring old generation, determining which types of generation to operate at a given time, and bidding on generation. In a future where renewables might have a larger impact on market mechanisms as well as financial outcomes, there is a need for modeling tools and power system modeling software that can provide policy makers and industry actors with more realistic representations of wholesale markets. These tools and analyses can also be represented by agent-based modeling frameworks. This paper discusses how key elements of current and future wholesale power markets can be modeled using an agent-based approach and how this approach may become a useful modeling paradigm to employ when studying power systems of the future.

This paper is organized as follows: Section 2 discusses some of the recent market design challenges that the electricity industry is facing. Section 3 gives an overview of how market manipulation can pose challenges, and it presents some of the most famous cases of market manipulation. Section 4 discusses the agent-based modeling paradigm and how it has been applied to electricity market modeling in the current literature. Section 5 concludes.

\footnotetext{
${ }^{1}$ See http://www2.epa.gov/cleanpowerplan/clean-power-plan-existing-power-plants.
} 


\section{Variable Generation and the Gaps in Current Market Design}

As the level of renewables on the electric grid increases, price suppressions coming from the deployment of zero-marginal-cost resources such as wind and solar may have a significant impact on the behavior of conventional generators and decision makers. This contributes to the discussions among power system industry actors and those who regulate it about how to design future electricity markets. Electricity market designs are hard to conceive, model, and implement, and integrating higher penetrations of renewables is only one of several challenges that must be considered.

\subsection{Merit Order Effect}

Recurring discussions in the electric power industry and market design forums are related to the merit order effect, which is the lowering of power prices in an energy market due to an increased supply of renewable energy. This seems to be of greater interest in Europe than it is in the United States because of Europe's higher penetrations of variable generation. High penetrations of renewables have been the focus of electricity market design discussions for some time, and there can be confusion when it comes to how they have changed or presumably will change the dispatch stack of current markets. In many instances, wind and solar power have pushed the merit order curve farther right and caused more expensive, conventional generators to be dispatched less frequently. Consequently, market-clearing prices decrease, either by becoming zero or negative. However, this happens not only when there are high penetrations of renewables; negative prices can also occur in systems that have relatively low penetrations of variable generation because of operational constraints on larger thermal stations.

Sometimes markets clear below zero without intermittent renewable generation as the marginal generator. This phenomenon should be considered a price formation issue of current wholesale electricity markets. These price distortions are caused by how energy policy mechanisms such as production tax credits are used. The effect happens to be "caused" by renewable resources such as wind and solar now, but in theory in the future this effect could be triggered by any generating resource that has low marginal costs. It is also worth noting that current price suppressions caused by wind generators bidding their production tax credits will be reduced when their incentives run out. Further, in the Nordic market, despite having a resource mix with low marginal costs and some drops, overall the system price seems to be consistently positive. (See Figure 1.)

The average clearing price in any given year in Nord Pool Spot, the leading electricity market in Europe, tends to fall in the range of $€ 20-46 / \mathrm{MWh}(\$ 20-50 / \mathrm{MWh})$ (see Figure 2). For example, in $201360 \%$ of the energy was produced by resources that had almost zero marginal production costs, and $23 \%$ was from resources that had marginal costs of less than $€ 10 / \mathrm{MWh}$. (Again, see Figure 1.) The Nordic market faces global forces that drive down the electricity price-for example, wet and dry years in Norway and Sweden that determine the availability of hydropower, the amount of wind that generates electricity in Denmark, and the use of different technologies to generate power during winter. These are different from the factors that drive prices down in the United States - for example, shale gas price combined with increased renewables. 

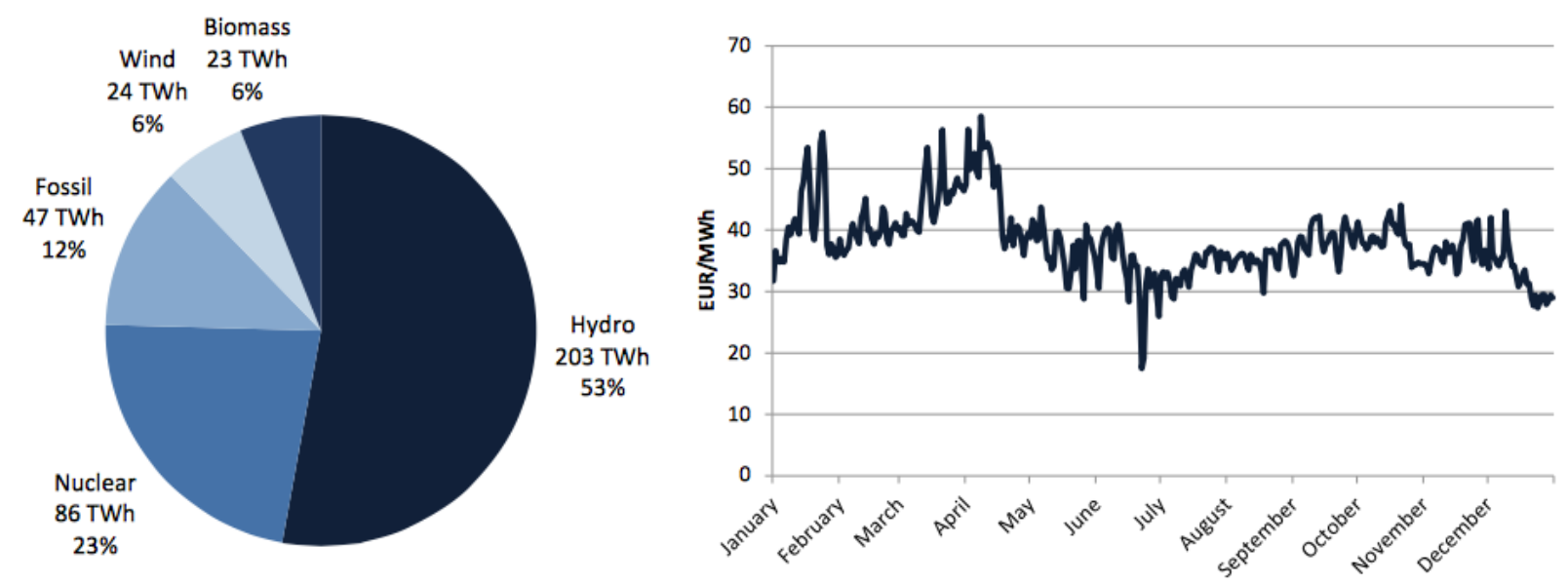

Figure 1. (Left) Power generation by source in the Nordic region in 2013 and (right) Nord Pool Spot system prices in 2013. Image from Nordic Energy Regulators (2014)

Instances of negative prices occurred in Northern and Central Europe, especially during the Christmas holidays that typically cause a drop in the energy demand. However, these events were also triggered by weather events (i.e., storms) that do not necessarily happen frequently in any of the affected countries. Stormy weather can increase the production of wind power and thus also increase the instances of negative prices, but this phenomenon will not necessarily persist to a level that will undermine the use of conventional generators and their ability to make money.

\subsection{Missing-Money Problem}

Another example of a market design flaw is the missing-money problem (Stoft 2002). This is a lack of monetary stream that can guarantee a recovery to some generators from their investments to pay for both variable and fixed costs (Ela et al 2014). This important issue affects current market participants. It also affects incentives to build new generation facilities if the electricity prices do not increase because of administrative actions, such as price caps.

The missing-money problem arises for several competing and compelling reasons, and the higher the share of renewables in the current power system, the more pressing this problem is because of the incentives that suppliers of electricity from these sources are facing, which typically suggest that market-clearing prices tend to be driven toward zero. The missing-money problem was predicted by electricity market theory (Joskow and Tirole 2007, Hogan 2005, Cramton and Stoft 2006. An illustration is provided in Figure 2. 


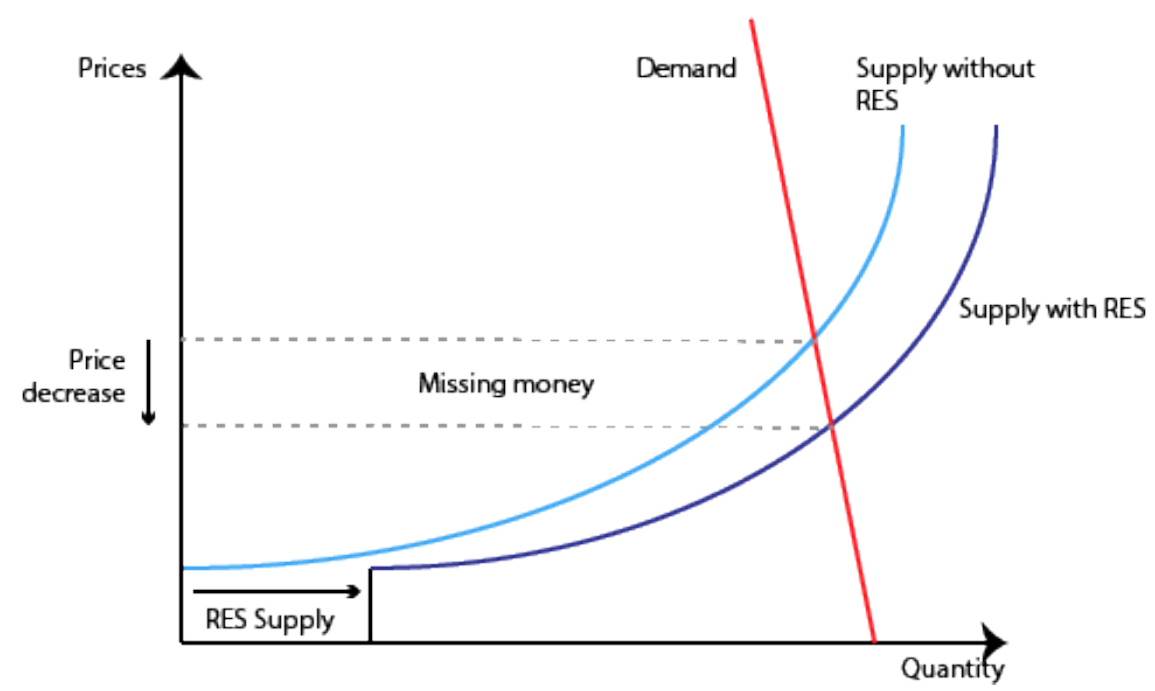

Figure 2. Illustration of the missing-money problem. Image by author

Traditional market designs that try to address the missing-money problem may include longerterm markets such as capacity markets (Cramton and Stoft 2005, Ausubel and Cramton 2010). These markets should incentivize new capacity in locations where it will be most needed in the future. They differ in product specification, commitment period, and price formation mechanisms. However, when capacity markets were first implemented, which was in New England, they showed basic and flaws that were unrelated to high penetrations of renewables, as for example the exercise of market power or the way how the level of needed supply was computed (Cramton 2003).

Historically, capacity markets were designed to prevent generation companies from exercising market power and to ensure that demand in future years would be met by adequate capacity. The deregulation of the electric sector promoted competition and the build-out of power plants. When the deregulation process started, there were no incentives or apparent motivations to establish capacity markets for the purpose of providing adequate returns to generators that were not actively participating in the newly formed markets. Also, these first capacity markets were not intended to provide incentives to build new capacity because there was enough to start with, units were not close to being retired, and variable generation was not posing any tangible challenge to operating electric power grids nor supplying enough electricity to depress prices.

Capacity markets can help ensure that there is sufficient generation and provide different sources of revenue streams even in scenarios with high penetrations of renewables (see Figure 3). In addition, they can address three pressing problems in current wholesale markets: investment, risk, and market power. Further, the operational challenges posed by growing shares of variable renewable generation can be substantially mitigated through a number of valuable and relatively low-cost measures (Hogan 2012).

A few wholesale market independent system operators (ISOs), including the Electric Reliability Council of Texas (ERCOT) and the Alberta wholesale market, rely on recovering costs from energy and on operating reserves, not capacity, and they employ scarcity pricing signals as a proper price signal to incentivize new generation. 
Scarcity pricing allows the price in real time to reach higher levels than the cost of the most expensive marginal generator in the system. These scarcity prices are typically based on administratively-set ancillary service scarcity prices, and they vary by region or country. When a system is not able to meet its ancillary service requirements, the administratively-set price will be high. Because energy and ancillary services are co-optimized, this price will also be reflected in the energy market. These prices, though difficult to predict in terms of investments in capital, can provide some needed revenue for capacity resources to recover fixed capital costs. Scarcity pricing represents a challenge to ISOs and market design because if the pricing level is inadequate it cannot provide investment incentives to build both conventional generation and renewable energy and transmission infrastructure.

However, scarcity pricing alone might not address the missing-money problem or revenue sufficiency in the future. Figure 3 shows that prices in ERCOT tended to reach the system-wide offer cap more infrequently during the last couple of years. This phenomenon is triggered when available operating reserves approach the minimum required levels to reflect the degradation in system reliability (Potomac Economics 2015). This is independent from the generators' offers, but it is part of the scarcity pricing mechanism procedures implemented by ERCOT.

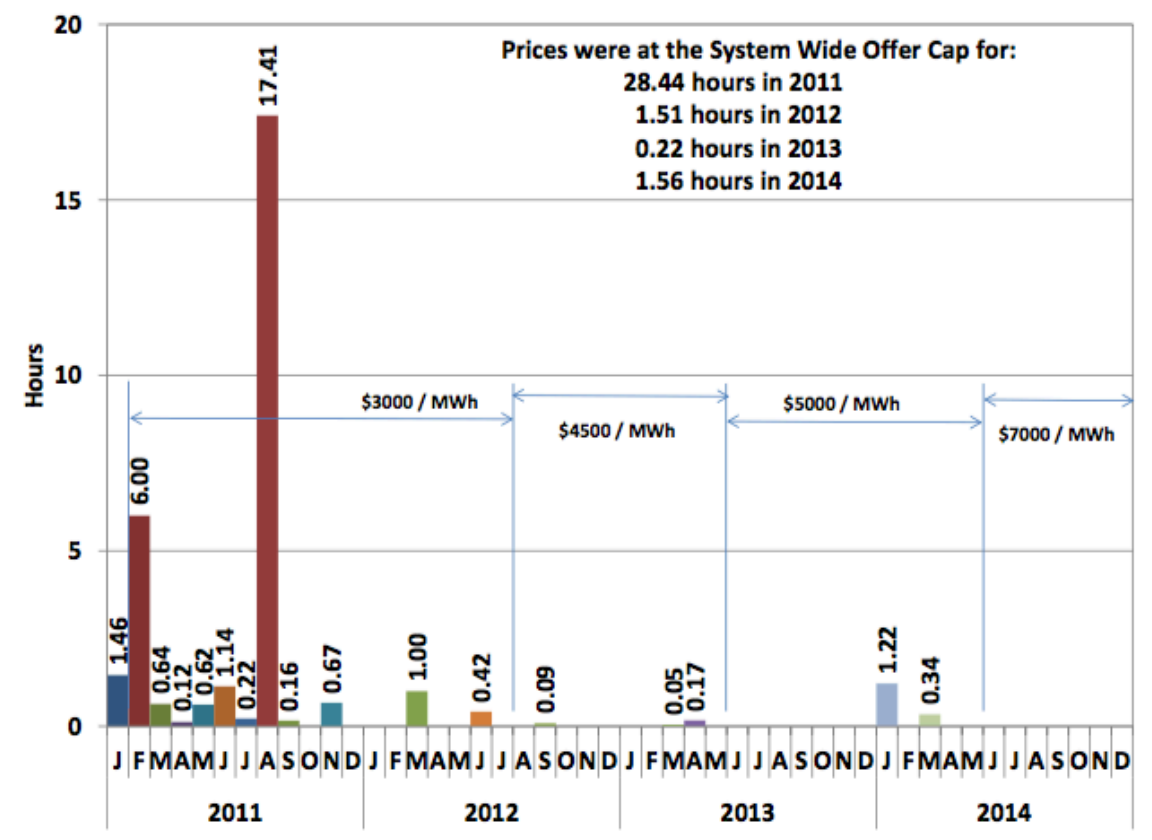

Figure 3. Prices at the system-wide offer cap in ERCOT. Image from Potomac Economics (2015)

ERCOT, which has an energy-only market, has recently changed the way in which scarcity prices are calculated. As a first step, the offer cap that limits the bid price of generation resources was increased to $\$ 9,000 / \mathrm{MWh}$ in June $2015 .^{2}$ Second, an operating reserve demand curve (ORDC) has been implemented in the real-time market (Hogan 2012). This means that the price of operating reserve will depend on the hourly probability of the lost load, which depends on the amount of operating reserve available - i.e., reserves that are available during the hour (offline)

\footnotetext{
${ }^{2}$ See Public Utility Commission of Texas Substantive Rules Applicable to Electric Service Providers $\$ 25.505-2$ (2012): https://www.puc.texas.gov/agency/rulesnlaws/subrules/electric/25.505/25.505.pdf.
} 
and reserves that are available immediately (online). These two values are added directly to the real-time energy price as a premium so that the additional revenue may help recover fixed costs. Possible events that could drive prices to the cap depend on factors such as weather, reserves available from the demand side, ramp constraints of the generators, and others. These contribute different weights to the way the two price adders are computed. For the complete mathematical formulation, see Hogan (2012).

Figure 4 shows the evolution of the ORDC price adders since their introduction in June 2014. The blue bars are the average real-time prices that include the ORDC price adders. The two green and red lines represent the average offline and online price adders that are added to the real-time prices. The graph shows that during summer 2015 the average value of the price adders was quite high, meaning that the reserve level during that period might have been lower than it was during the previous months. In August 2015, Texas experienced its current all-time peak demand record, 68,912 MW, which was reached between 4 p.m. and 5 p.m. Central Daylight Time on August 6, which broke the previous record of 68,459 MW set a day before. Before that week, the record was 68,305 MW, which was set on August 3, 2011. The high temperatures$102^{\circ} \mathrm{F}$ up to $111^{\circ} \mathrm{F}$ - that were experienced in Texas in August drove prices high and forced ERCOT to issue an extreme hot weather advisory.

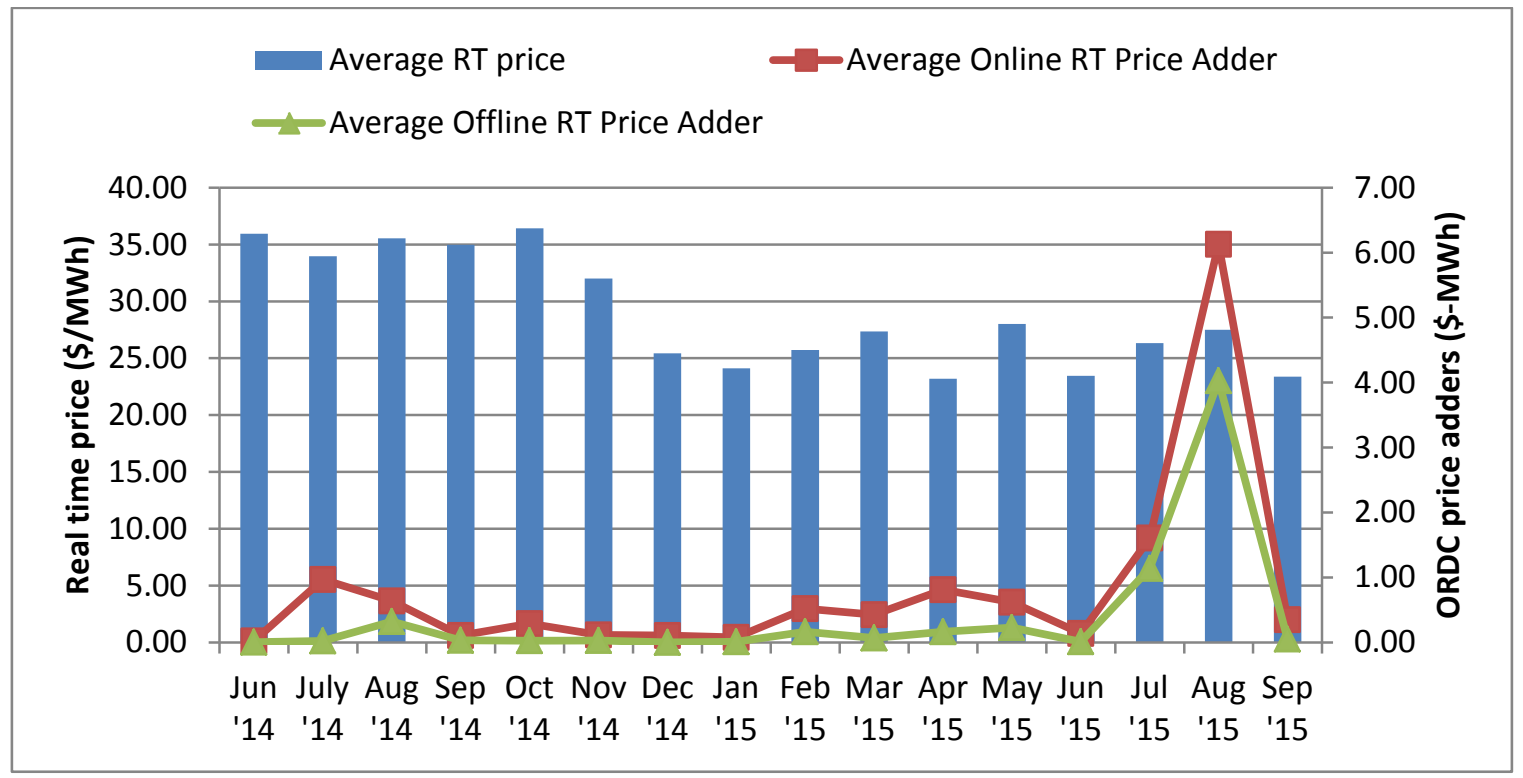

Figure 4. Evolution of the ORDC price adders since their introduction in June 2014. Image by author based on calculations derived from publicly available data from ERCOT ${ }^{3}$

It is worth noting that the ORDC price adders take into consideration that the demand side participates and provides reserves during real time, hence the demand side of the market is going to play a major role in future markets. Indeed, all ERCOT monthly operational overview documents prepared for the Public Utility Commission of Texas between June 2014 and now show that the majority of daily instances when the real-time, offline, reserve price adder was relatively high were due to an increase in load that outpaced the generators coming online. In

\footnotetext{
${ }^{3}$ See http://www.ercot.com/mktinfo/rtm/index.html.
} 
other circumstances, however, the high values - the highest was \$932.24/MWh in August 2015, and the average is approximately $\$ 40 / \mathrm{MWh}$ - were also due to the low levels of offline and online reserve capacity. ${ }^{4}$ Therefore, a careful understanding about how price adders affect the energy market is crucial. The missing-money problem has other important implications as well, and these have more to do with how electricity markets are designed and less with the role that renewables have in making these flaws evident.

\subsection{Uplift Payments}

The integration of more renewables coupled with the need for more flexibility in electric power systems has given rise to more interest in the ability of market participants to obtain revenue streams in the marketplace through uplift payments ${ }^{5}$ (Hogan 2006, Gribik et al. 2007). Because of the discrete nature of unit commitment, power plant owners need to consider numerous technical constraints to reliably operate their power plants, and a number of technical and operational limitations impact market outcomes. These conditions do not allow for perfect, complete, full modeling representations of a power system's physical constraints, and when these constraints cause issues, they seldom force a system operator to manually dispatch resources that can help resolve them (FERC 2014). On one hand, manual operations help guarantee the reliability of the grid; but on the other hand, they do not reflect the true marginal cost of electricity and can ultimately hinder the economic competitiveness of electricity markets. In 2012, the members of the Market Surveillance Committee of CAISO were asked to provide an opinion on bid cost recovery (BCR) mitigation, because the BCR might provide an incentive for generators to have a strategic behavior aimed at increasing BCR payments (Bushnell et al. 2012). An example is the "incentive, for instance, for a generating unit to receive a day-ahead BCR payment based on a day-ahead commitment, and then to declare an outage so that the unit would not actually run but would still receive the payment, or for a unit to receive BCR for generation in excess of ISO dispatch instructions" (Bushnell et al. 2012). The next chapter discusses uplift payments and how they have been recently gamed.

\footnotetext{
${ }^{4}$ See the "ERCOT Monthly Operational Overview 201508" available from http://www.ercot.com/committees/board. ${ }^{5}$ Uplift payments are payments made to the generators. These are different from uplift charges, which are to be paid by the generators. For a more detailed description, see FERC (2014).
} 


\section{Greed and Market Manipulation}

An important piece of market design is to define the set of rules that can prevent gaming and can ensure intervention in case manipulations were to happen.

Electricity markets have several properties that justify some level of market intervention by a regulating authority, especially after several parties have recognized that some implicit structural impediments can hinder effective competition and lead to actions that can affect the correct, fair, economic outcomes of the markets.

The California electricity crisis was a situation in which California had a shortage of electricity supply caused by market manipulations, illegal shutdowns of pipelines by Enron, and capped retail electricity prices. FERC investigated the alleged manipulation of the electricity market by Enron and other energy companies and their role in the crisis. Enron became famous from the Death Star strategy, by getting paid to move energy to relieve congestion without actually moving energy or relieving congestion. Through "megawatt laundering," Enron was selling its electricity across state boundaries and then reselling it back into California at higher prices.

The Enron scandal in 2001 is probably one of the most known business failures to have happened in the electric power industry worldwide. The firm's bankruptcy showed how electricity markets could be gamed to a very dangerous extent.

Prior to the crisis in the California electricity market, competition policies at FERC had primarily focused on creating competitive market structures that could be relied upon to produce just and reasonable rates. However, in Order 2000, FERC also acknowledged that market monitoring was a core function of newly forming regional transmission organizations. In approving the establishment of ISOs in the eastern United States, FERC approved market power mitigation protocols that gave the ISOs limited power to review and regulate generator offer prices under certain conditions, such as situations in which there are local transmission network constraints.

Following the Enron scandal and in the aftermath of the California electricity crisis, FERC gained more oversight power on restructured electricity markets in the United States. Based on the Energy Policy Act of 2005, FERC now imposes penalties on entities that manipulate the electricity and natural gas markets. In this regard, a set of market mitigation rules and subsequent techniques to prevent Enron-like events have been placed in all electricity markets in the United States:

In the wake of manipulative schemes by Enron and others in the western U.S. electricity markets, Congress, through the Energy Policy Act of 2005, amended the FPA to give the Commission broad authority to prohibit energy market manipulation. In relevant part, FPA section 222, 16 U.S.C. $\S 824 \mathrm{v}(\mathrm{a})$, makes it "unlawful for any entity ... directly or indirectly, to use or employ, in connection with the purchase or sale of electric energy ... any manipulative or deceptive device or contrivance ... in contravention of such rules and regulations as the Commission may prescribe as necessary or appropriate in the public interest or for the protection of electric ratepayers" (FERC 2015). 
All regulated U.S. ISO markets are also monitored by in-house market-monitoring units - these differ in size, roles, and actions; see Goldman, Lesieutre, and Bartholomew (2004) for a review — and by independent market monitors that are responsible for promoting robust, competitive, and nondiscriminatory electric power markets. The latter typically collect available data; design market metrics; monitor participant conduct, behavior, and market performance; and publish quarterly and annual reports that discuss the overall competitive assessment of each of the monitored markets in the preceding year.

These analyses involve discussions about the potential for market manipulation typically triggered by economic and physical withholding and the effectiveness of the market mitigation measures that are employed to prevent suppliers from exercising market power. For a review, see Twomey et al. (2006).

Another recent example of market manipulation is the case of JP Morgan Ventures Energy Corp. (JPMVEC), ${ }^{6}$ which showed how uplift payments can be used to earn huge profits from the California and the Midwest markets during a two-year period.

FERC and its investigation team focused on several bidding strategies that JPMVEC traders used to exploit the bid-cost recovery rule in CAISO to increase their market revenues (FERC 2013). In total, the energy-trading unit was involved in five market-gaming strategies in CAISO from September 2010 to June 2011 and three gaming strategies in the Midcontinent ISO from October 2010 to May 2011.

The strategy that was implemented to game the BCR payments involved some power plants that had previously been running infrequently and at a loss for almost eight months but afterward were running more often and were also very profitable. The JPMVEC generators would submit bids to CAISO at a bundled price for the energy produced at the minimum generation level (Pmin) that the plant could reliably produce. For example, the energy bids would be at a perMWh price of approximately $\$ 90 / \mathrm{MWh}$, and the day-ahead market prices in CAISO during this period averaged $\$ 30$ to $\$ 35$ (FERC 2013).

If CAISO committed a unit in the day-ahead market, it was obligated to pay the unit at least its stated price for the Pmin energy, even if that price was above the market rates. Hence, if JPMVEC's bids resulted in a day-ahead award, JPMVEC would be paid as bid (at \$90/MWh) for its Pmin energy, at twice its costs, even if the market prices were much lower.

These strategies were designed to try to achieve an overall average energy price to secure dayahead awards from CAISO. Once this happened, JPMVEC was assured of being paid, at a minimum, twice its costs of running at Pmin.

However, if a generator received a day-ahead award for energy above Pmin, it may not have actually produced that energy, and it may have "bought back" its day-ahead award, paying another generator to produce that energy in the real-time market. This generator would be decreased down to its minimum generation level and would be told by CAISO (or "dispatched") to run at that level.

\footnotetext{
${ }^{6}$ See http://www.wsj.com/articles/SB10001424127887324170004578637662037547582.
} 
Hence, JPMVEC's strategy that gamed the BCR payments followed the bidding scheme described above, and the generators were paid (as BCR) their full bid price (e.g., \$90/MWh) for their Pmin energy even when the market prices averaged $\$ 30$ to $\$ 35 / \mathrm{MWh}$. In addition, JPMVEC received market revenues (i.e., the amount it was paid at market rates in the day-ahead market less its real-time buyback expense) for the same energy.

During that period, JPMVEC received \$14 million in market revenues from CAISO, and their gas and other operating costs were $\$ 17.7$ million: the units lost millions of dollars at market rates but had a profit of approximately $\$ 20$ million (on a basis of marginal cost) because of the BCRs (FERC 2013).

Despite the bad light under which uplift payments are seen now, they are supposed to allow plants to recover these costs if market revenues are not sufficient to avoid discouraging them from participating during the hours when they are really needed. However, they are a concern for many in the industry because there is not disclosure or transparency about how these payments are made, under which circumstances, or predictable amounts.

Indeed, stemming from their technical workshops on evaluating matters affecting price formation in the energy and ancillary services markets, FERC has analyzed uplift payments made by the several ISOs from 2009-2013 in an attempt to gain more insight about how and if uplift payments can affect market outcomes and undermine the effectiveness of price signals and reduce market efficiency (FERC 2014).

The major outcomes of this analysis are as follows:

- Uplift payments have been highly concentrated and recur on a geographical or resource basis.

- They are closely related to market fundamentals, including energy and fuel costs.

- They are also closely related to price divergences between day-ahead and real-time markets.

The strong correlation between uplift credits and price spreads between the day-ahead and realtime markets suggests that the accuracy of commitment decisions may strongly influence uplift and day-ahead and real-time price differences in ISO markets. The need for more accuracy in representing decision-making processes in market design and modeling is paramount, as is a deeper understanding and a possible way of "pre-screening" possible scenarios.

With the increasing complexity in market design and power system operations, it is quite clear that more attention and consideration must be made to the behavioral aspects of electricity markets. A shift may be needed in the approach toward new market design challenges as well as power systems and integration studies. 


\section{Challenges to Modeling Current and Future Electricity Markets}

With the advent of zero-marginal-cost energy sources, market operators and regulatory frameworks are trying to address the related issues for conventional generators, either by creating new market structures or by adding more complexities to existing ones. Current electricity markets have singular characteristics compared to other commodities markets, which can affect how participants perceive the market signals needed to contribute to system reliability, offer flexibility into the market, or construct new generation resources.

Standard power system modeling software are useful when performing analyses on the existing or predicted future electricity infrastructure, but they are not flexible enough to provide what-if scenarios about how generator behaviors will impact market operations. Traditional research tools for grid industry policy making that are based on a rational representative agent maximizing its own utility in a general equilibrium framework are unable to accurately predict and cope with some of today's most pressing challenges, such as renewable portfolio standards.

Integrating increasing penetrations of renewables in current and future power systems is a demanding task that requires technical knowledge of power systems as well as an understanding of the possible decisions that those who operate grids and power plants face every day. There seems to be some sort of epistemological separation between electricity market design studies and the way the industry represents power systems and how electric grids are operated. Indeed, most renewable integration research that has been conducted to date assumes a future wherein conventional and renewable generators are risk-neutral and offer their true technical capabilities, at their true costs, into large centralized markets for electricity and balancing services. However, historical bids into these markets may reveal insights into strategies from individual participants that influence market outcomes.

Figure 5 shows example bids from generators in ERCOT. The analysis has been performed on publicly available day-ahead market disclosure reports available on ERCOT's website. ${ }^{7}$ The left histogram shows the frequency of bids from a simple-cycle gas turbine generator (which has a marginal cost in the range of $\$ 30-\$ 50 / \mathrm{MWh})$, and the right histogram shows the same information for a coal generator (which has a marginal cost in the range of $\$ 20-\$ 30 / \mathrm{MWh}$ ). Although most of the offers for both generators are similar to operational costs, both generators bid much higher than marginal costs $15 \%-25 \%$ of the time.

\footnotetext{
${ }^{7}$ See http://www.ercot.com/mktinfo/reports/index.html.
} 

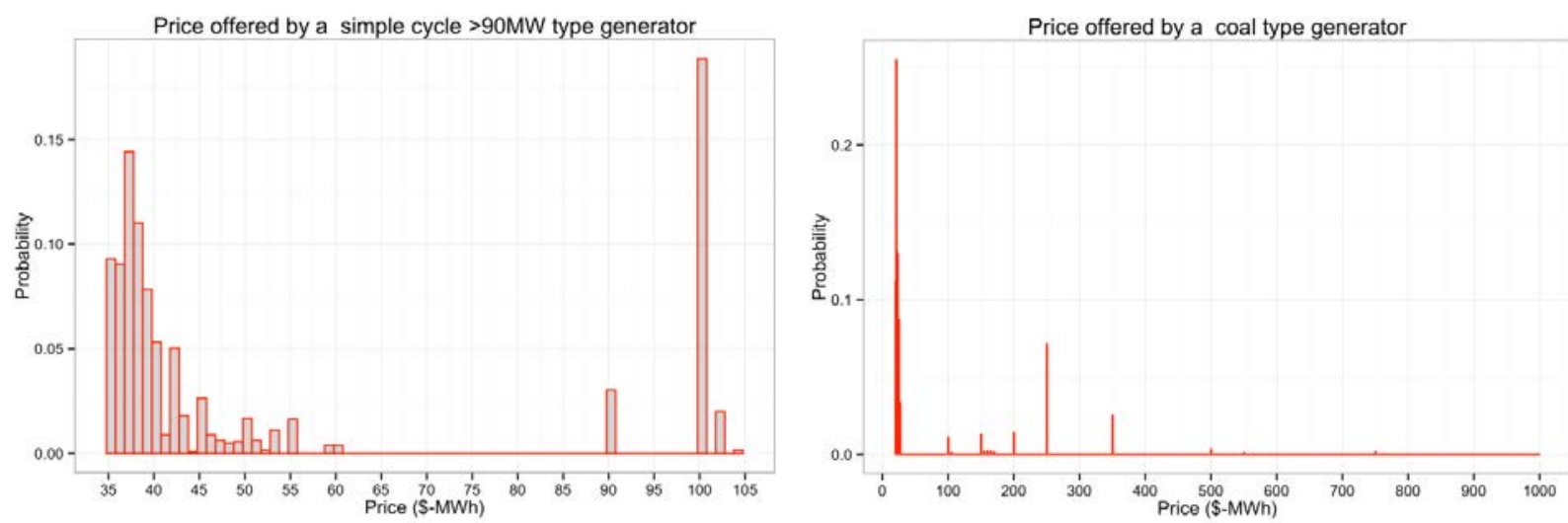

Figure 5. Example bids from generation in ERCOT during a yearly period. These histograms show that although most bids are clustered around the operational cost of producing energy, some of the bids are many times larger than the marginal costs. Images by author based on data publicly available from ERCOT

The type of real-world market behavior discussed above is typically not captured in research on the grid integration of renewable energy. However, behavioral modeling is necessary to fully capture the impact of the strategic decisions that individual market participants make to influence prices and increase their profits. Behavior modeling can also capture the impacts of strategies driven by risk preferences, complex cost structures, and physical constraints.

Further, planning studies typically assume that generators have either a linear or a polynomial heat rate curve that does not translate into an offer curve. In reality, as shown in Figure 6, generators can change their offer bids from one month to another. The two graphs show how the same generator changed its offer curve in two subsequent months, and, in particular, the offer curve shown in the right graph does not reflect its marginal costs. Aside from the specific reasons that lead to this type of offer, which are not the focus of this paper, these types of dynamic bidding behaviors are not represented in traditional power system modeling studies. Hence, behavioral simulations become crucial to assess how market participants can react to current market mechanisms, institutional changes, and new market rules and to more accurately represent future markets with high penetrations of variable generation. 

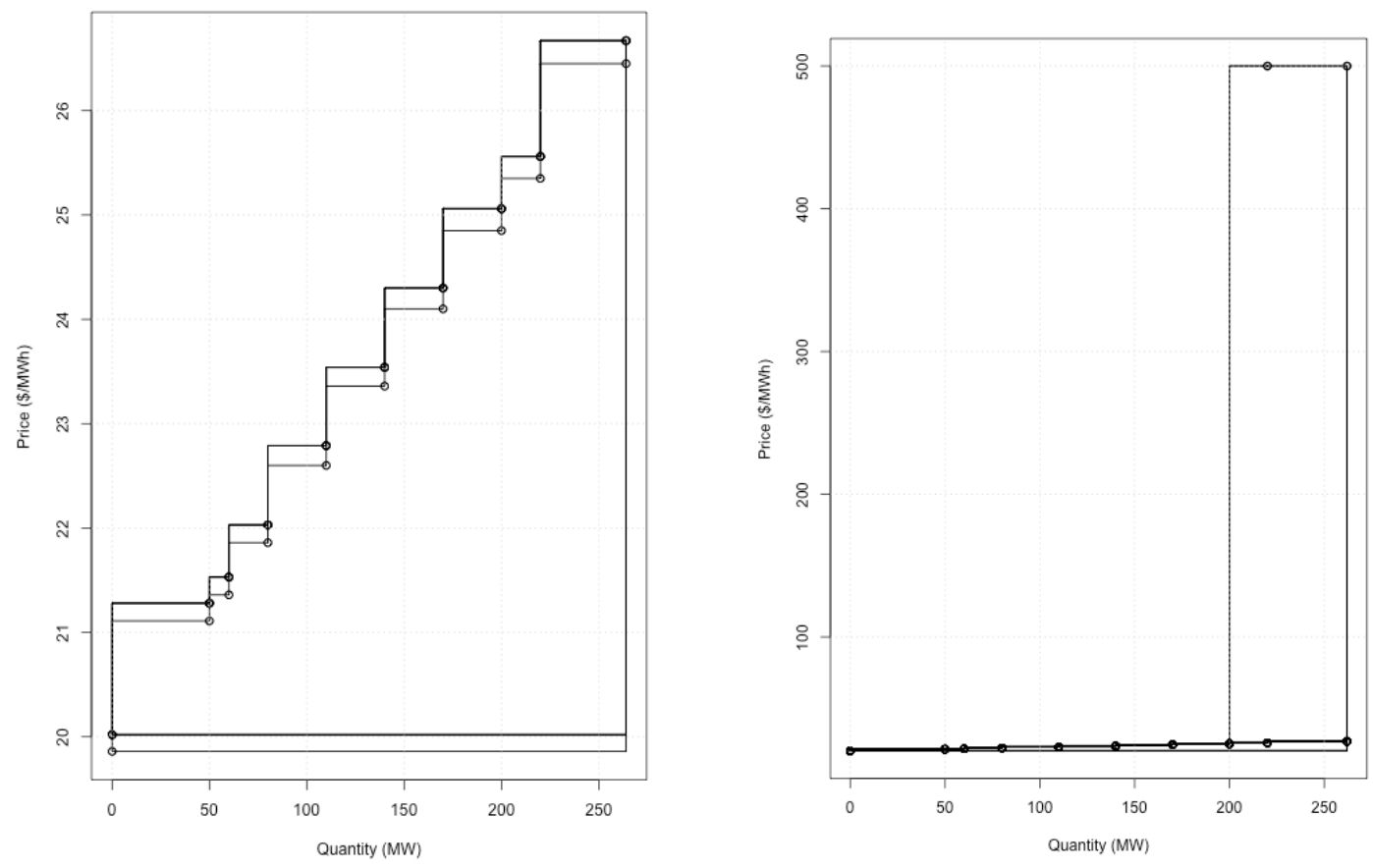

Figure 6. Example bids from generation in ERCOT during a yearly period. These two graphs show that a generator changed their offer curves in two months, and (left panel) they bid many times larger than their marginal costs. Images by author based on data publicly available from ERCOT 


\section{Behavioral and Agent-Based Modeling of Electricity Markets}

Electric power systems are changing at a fast pace and becoming increasingly complex from both an economical and a technological viewpoint. This has required system operators and power systems and economics researchers to acquire new competencies and adopt innovative research approaches to study realistic market scenarios and propose appropriate regulations for the market environment.

Several approaches have been proposed in the electricity market literature. As discussed above, classical analytical power system models do not represent some important market behaviors and outcomes because they are a loose fit to electricity market modeling. Similarly, standard analytical economic approaches that are based on game-theoretic models are usually limited to simplified market simulations among few actors, and they neglect technological and economic constraints such as transmission networks. Further, modeling aspects such as repeated interactions among market operators, market frictions between two or several ISOs, transmission network constraints, incomplete information, and multi-settlement market mechanisms are seldom addressed by literature on electricity market theoretic models. Conversely, computational methodologies offer an appealing approach to cope with the complexity of power market mechanisms by enabling researchers to realistically simulate such market environments.

Agent-based computational economics (Tesfatsion and Judd 2006) modeling is well suited for undertaking institutional studies such as testing current and future electricity market designs. Agent-based computational economics modeling begins with assumptions about "agents" and their interactions and then uses computer software to generate simulations that reveal the dynamic consequences of these assumptions (Tesfatsion and Judd 2006). Agents can range from passive structural features that have no cognitive function to individual and group decision makers that have sophisticated learning and communications capabilities (Tesfatsion and Judd 2006). Agent-based models are intrinsically designed to handle complex systems, and they allow researchers to construct test beds in the form of computational virtual worlds (Bunn and Oliveira 2003, Conzelmann et al. 2005, Sun and Tesfatsion 2007, Praca et al. 2003, Weidlich and Veit 2008, Cincotti and Gallo 2013. Starting from user-specified initial conditions, world events are driven entirely by agent interactions; the counterexample is given by production cost modeling studies that assume least-cost dispatch as well as no interaction among the agents (i.e., generators, generation companies, load-serving entities) that "populate" their models (see Figure 7). 

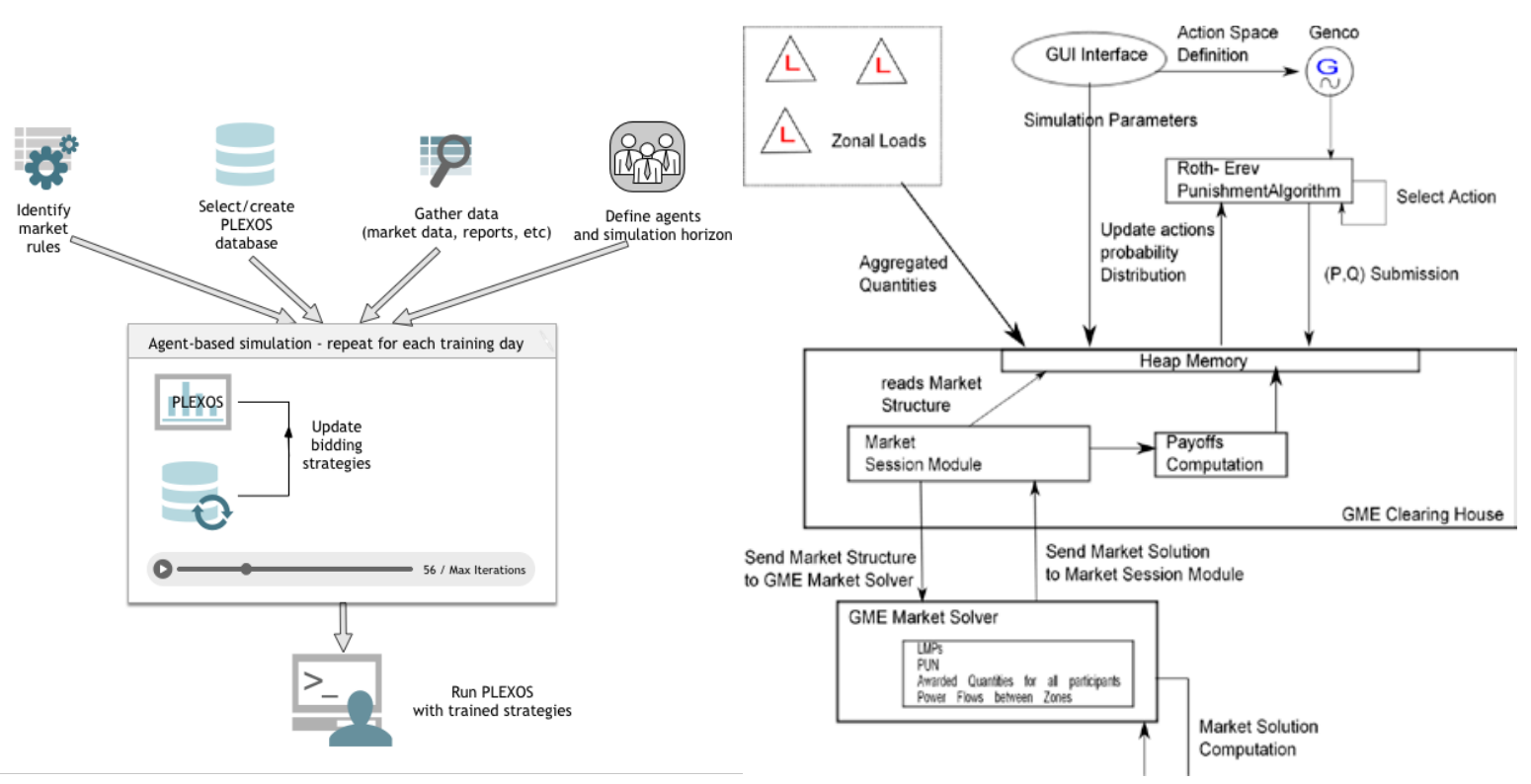

Figure 7. Flowchart of agent-based modeling frameworks. Images from (left) Gallo (2015) and (right) Cincotti and Gallo (2013)

Multi-agent models have been proposed to overcome several shortcomings of current power systems models (Tesfatsion and Judd 2006, Gallo 2015). In these models, agents are heterogeneous, and they are endowed with limited information and computational capabilities. These computational frameworks provide powerful software tools for economics wherein experiments concerning scientific hypotheses and policy design issues can be performed (Tesfatsion and Judd 2006). They address the interactions and the coordination processes of heterogeneous economic agents by means of their individual and social learning mechanisms, the emergence of aggregate statistical regularities in the economy, and the occurrence of market failures - e.g., asymmetric information, imperfect competition, and coordination failures. Consequently, economic multi-agent systems have gained attention during the last decade. In the past few years, a number of studies have pointed out the benefits of agent-based frameworks for economic policy design; see Buchanan (2009), Farmer and Foley (2009), and LeBaron and Winkler (2008).

An agent-based approach can avoid the lack of realism in the optimizing agent assumption by using a realistic description of agent behaviors and interactions. This approach allows us to introduce elements of "behavioral economics." Increasing literature strands support the evidence of agent-based and heuristic decisions (Kahneman and Tversky 1984, Gigerenzer and Selten 2002). Indeed, agent-based models can represent bounded rational agents with adaptive and learning capabilities (Simon 1955, Kirman 2011). By modeling individual economic agents on the micro level and aggregating their behavior on the macro level, artificial economies can be constructed that are "richer" than the traditional macro models. The advantages of economic agent-based models are primarily the possibility to model the individual decision-making process of each agent alongside their interactions by means of decentralized market or hierarchical relationships. 
Agent-based models have been successfully used to show how the impact of institutional designs changes can affect how market participants behave (Tesfatsion and Judd 2006) and to test how the impact of high penetrations of renewables can affect bidding behaviors as well as the revenues streams of different market participants (Gallo 2015).

Current agent-based test beds (Conzelman et al. 2005, Praca et al. 2003, Weidlich and Veit 2008, Sun and Tesfation 2007, Cincotti and Gallo 2013) have shed light on a variety of electricity market features using test cases and projecting the aggregated results onto existing U.S. and European ISOs. These test beds are limited in their applications by several factors, such as the availability of realistic operational models of wholesale electricity markets or bid data. Gallo (2015) attempted to evaluate the impact of strategic behavior, risk aversion, and increasing levels of renewables and presented the Agent-Based Framework for Renewable Energy Studies (ARES), an integrated research approach that adds an agent-based model of industry actors to PLEXOS and combines the strengths of the two to overcome their individual shortcomings. ARES has been demonstrated by studying how increasing levels of wind could impact the operations and the exercise of market power of representative generation companies that exploit an economic withholding strategy. The analysis was carried out on a test system that represents the ERCOT energy-only market in the year 2020. In particular, the author studied how these generation companies that are deemed to have and exercise market power do so in the ERCOT market by reproducing their decision-making processes. Given the novelty of this modeling approach, the author presented some differences between a standard, least-cost, production modeling simulation and a behavioral one. The agent framework improved the realism of the model as follows: it increased generator profits compared to simple marginal-cost bidding; and the level of the market prices was higher when strategic resources tried to increase their profits, bidding their true production costs and a markup (see Figure 8).
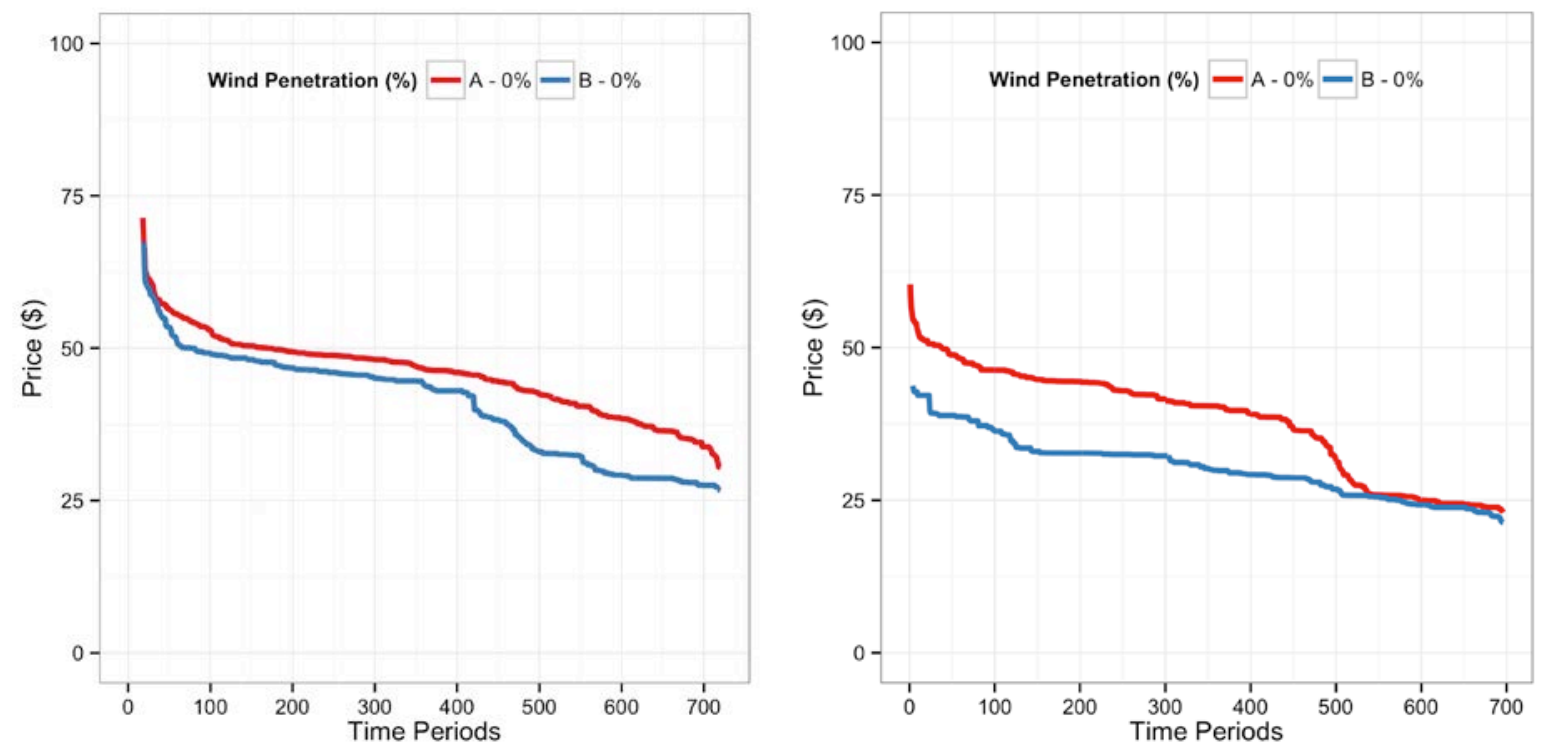

Figure 8. Price duration curve comparison between the (left) high demand scenario and (right) low demand scenario. Baseline scenario = B, agent-based scenario = A. Images from Gallo (2015) 
The bidding strategy helped the agents to supply less energy but at a higher economic reward. However, the impact of high penetrations of wind reduced the ability of the agents to manipulate the prices and to make profits in the ERCOT market.

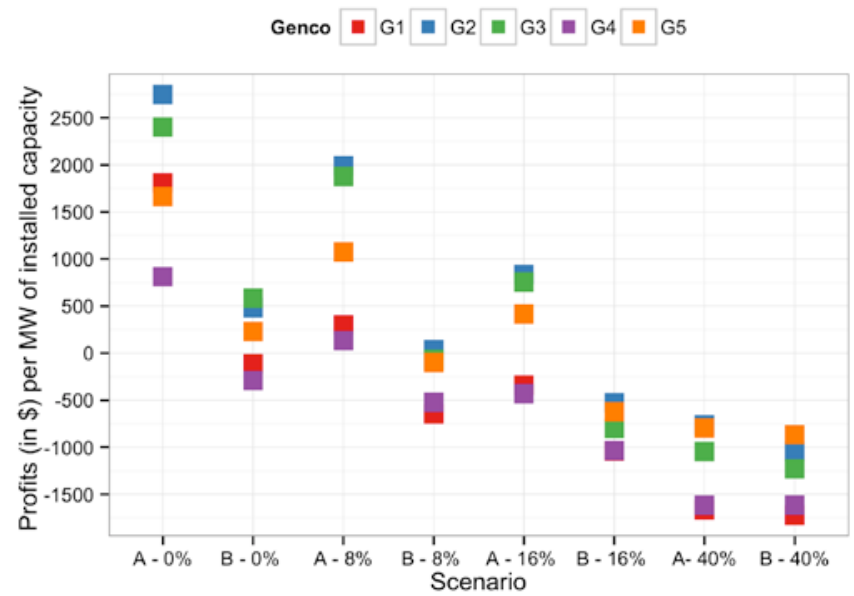

Figure 9. Distribution of each agent profits within the simulation. Profits have been normalized by each agent total capacity. Baseline scenario $=\mathrm{B}$, Agent-based scenario $=$ A. Image from Gallo (2015)

The results obtained with the agent framework reproduce with more realism the operations of an energy market under different and increasing wind penetrations. A critical issue for agent-based models is represented by their validation, which is of extreme importance to their success and their usage as a modeling tool. This problem is generic for every researcher engaged in the behavioral representation of economies. Electricity markets around the world are characterized by distinctive phenomena: these features are typically called stylized facts (LeBaron and Winkler 2008; Weron, Bierbrauer, and Trück 2003). Examples of these features are price jumps or spikes, extreme volatility, seasonality, mean reversion, and an underlying probability distribution that follows power law or is hyperbolic and exhibits heavy tails (see Figure 10). Any agent-based model that represents an electricity market should try to mimic these features to reliably and accurately depict reality and to be eventually used to forecast electricity market prices (Cincotti et al. 2014). On the contrary, the purpose of agent-based models is not to predict the future but rather to provide insights into the possible evolution of current and future electricity markets and envisage ranges of possible outcomes and solutions, because the main purpose of modeling per se is not to create an exact replica of all the details of the system under study but to give a realistic representation of it. 


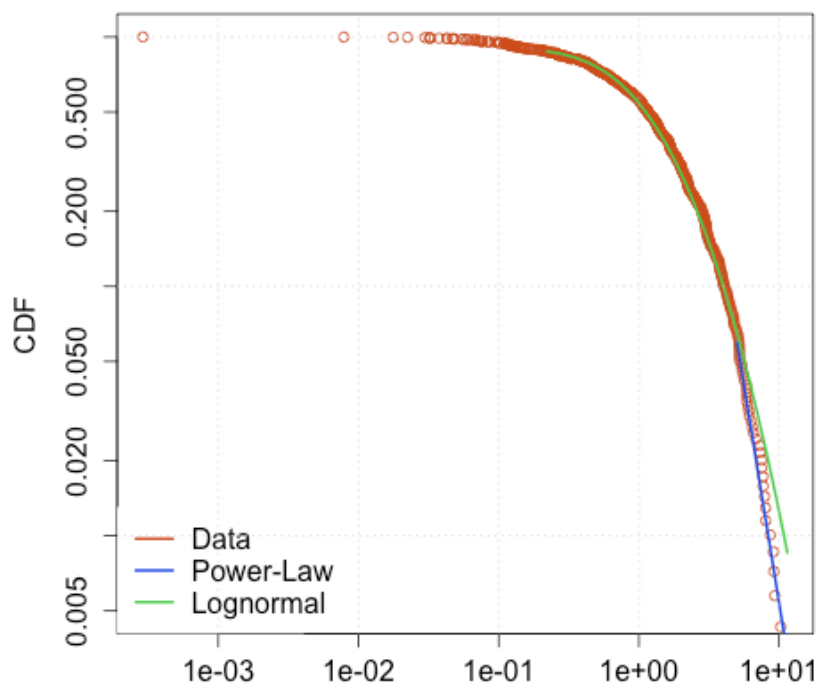

Figure 10. Fat-tail phenomenon observed in one sample of market prices obtained with ARES. Image from Gallo (2015) 


\section{Conclusions}

Integrating increasingly high levels of variable generation in U.S. electricity markets requires addressing not only power system and grid modeling challenges but also an understanding of how market participants react and adapt to them. The need is urgent for modeling tools that can assist and inform policy makers in their decision-making processes, that can help market design experts evaluate different scenarios, and that can provide power system operations insight to system planners and operators. A number of technological, modeling and planning barriers stand in the way to more accurately modeling and building power systems under high penetrations of renewable generation, the biggest of which is that effective decision making requires a multidisciplinary approach among all electric power system industry actors. Convincing methods and tools are needed that are able to guide efficient and effective decision-making processes that are capable of detecting emergencies, anticipating future events, and evaluating the impact of different policy choices. If policy makers are able to use these methods and tools to investigate and evaluate different scenarios, they will be more informed, and more informed policy makers lead to better decisions. A combination of production cost modeling simulations and agent-based models can help achieve these goals. 


\section{References}

Abdul-Rahman, K., H. Alarian, M. Rothleder, P. Ristanovic, B. Vesovic, and B. Lu. 2012. "Enhanced System Reliability Using Flexible Ramp Constraint in CAISO Market." In IEEE Power and Energy Society General Meeting Proceedings. Piscataway, NJ: Institute of Electrical and Electronics Engineers.

Ausubel, L.M., and P. Cramton. 2010. "Using Forward Markets to Improve Electricity Market Design.” Utilities Policy 18(4): 195-200.

Buchanan, M. 2009. "Economics: Meltdown Modelling.” Nature 460: 680-682.

Bunn, D., and F. Oliveira. 2003. "Evaluating Individual Market Power in Electricity Markets via Agent-Based Simulation.” Annals of Operation Research 121: 57-77.

Bushnell, J., S. Harvey, B. Hobbs, and S.S. Oren. 2012. Opinion on Bid Cost Recovery Mitigation Measures and Commitment Cost Refinements (Technical Report). Folsom, CA: Market Surveillance Committee of the California ISO.

CAISO. 2011. Opportunity Cost of Flexible Ramping Constraint: Draft Final Proposal (Technical Report). Folsom, CA. Accessed October 2015: http://www.caiso.com/Documents/DraftFinalProposal-FlexibleRampingConstraint.pdf.

CAISO. 2015. "Fast Facts: What the Duck Curves Tells Us About Managing a Green Grid." Folsom, CA. https://www.caiso.com/Documents/FlexibleResourcesHelpRenewables_FastFacts.pdf.

Cincotti, S., and G. Gallo. 2013. "The Genoa Artificial Power-Exchange.” In Agents and Artificial Intelligence, vol. 358, edited by J. Filipe and A. Fred, 348-363. Heidelberg, Germany: Springer Berlin.

Cincotti, S., G. Gallo, L. Ponta, and M. Raberto. 2014. "Modeling and Forecasting of Electricity Spot-Prices: Computational Intelligence vs. Classical Econometrics." AI Communications 27(3): 301-314.

Conzelmann, G., G. Boyd, V. Koritarov, and T. Veselka. 2005. "Multi-Agent Power Market Simulation Using EMCAS.” In IEEE Power Engineering Society General Meeting Proceedings $3,2,829-2,834$.

Cramton, P. 2003. "Electricity Market Design: The Good, the Bad, and the Ugly." In Proceedings of the IEEE 36th Annual Hawaii International Conference on System Sciences. Piscataway, NJ: Institute of Electrical and Electronics Engineers.

Cramton, P., and S. Stoft. 2005. "A Capacity Market That Makes Sense.” The Electricity Journal 18(7): 43-54.

Cramton, P., and S. Stoft. 2006. "The Convergence of Market Designs and Adequate Generating Capacity." White Paper for the Electricity Oversight Board. 
Denholm, P., M. O' Connell, G. Brinkman, and J. Jorgenson. 2015. Overgeneration from Solar Energy in California: A Field Guide to the Duck Chart (Technical Report) NREL/TP-6A2065023. Golden, CO: National Renewable Energy Laboratory.

Ela, E., M. Milligan, A. Bloom, A. Botterud, A. Townsend, and T. Levin. 2014. Evolution of Wholesale Electricity Market Design with Increasing Levels of Renewable Generation (Technical Report) NREL/TP-5D00-61765. Golden, CO: National Renewable Energy Laboratory.

Farmer, J.D., and D. Foley. 2009. "The Economy Needs Agent-Based Modelling." Nature 460: 685-686.

FERC. 2011. Demand Response Compensation in Organized Wholesale Energy Markets, 134 FERC \ 61,187, Order No. 745, FERC Stats. \& Regs., March 15. Accessed October 2015: http://www.ferc.gov/EventCalendar/Files/20110315105757 -RM10-17-000.pdf.

FERC. 2013. In re Make-Whole Payments and Related Bidding Strategies (JP Morgan Ventures Energy Corporation), 144 FERC $961,068$.

FERC. 2014. Staff Analysis of Uplift in RTO and ISO Markets, August 14. Accessed October 2015: https://www.ferc.gov/legal/staff-reports/2014/08-13-14-uplift.pdf.

FERC. 2015. Petition for Order Affirming the Federal Energy Regulatory Commission's July 2, 2015, Order Assessing Civil Penalties Against City Power Marketing, LLC, and Stephen Tsingas. http://www.ferc.gov/enforcement/civil-penalties/actions/2015/FERCvCityPower.pdf.

Gallo, G., 2015. "An Integrated Agent-Based and Production Cost Model for Renewable Energy Studies: Preprint." Presented at the 49th Hawaii International Conference on System Sciences (HICSS), Kauai, Hawaii, January 5-8, 2016.

Gigerenzer, G., and R. Selten. 2002. Bounded Rationality: The Adaptive Toolbox. Cambridge, MA: MIT Press.

Goldman, C.A., B.C. Lesieutre, and E. Bartholomew. 2004. A Review of Market Monitoring Activities at U.S. Independent System Operators (Technical Report). Berkeley, CA: Lawrence Berkeley National Laboratory.

Gribik, P.R., W. Hogan, and S. Pope. 2007. "Market-Clearing Electricity Prices and Energy Uplift.” Working paper.

Hogan, M. 2012. What Lies "Beyond Capacity Markets”? (Technical Report). Brussels, Belgium: Regulatory Assistance Project. http://www.raponline.org/document/download/id/6041.

Hogan, W. 2005. On An “Energy Only” Electricity Market Design for Resource Adequacy (Technical Report). Cambridge, MA: Harvard University.

Hogan, W. 2006. "Revenue Sufficiency Guarantees and Cost Allocation." Comments submitted to FERC, Docket No. ER04-691065. 
Hogan, W. 2012. Electricity Scarcity Pricing Through Operating Reserves: An ERCOT Window of Opportunity (Technical Report). Cambridge, MA: Harvard University.

Joskow, P., and J. Tirole. 2007. "Reliability and Competitive Electricity Markets.” RAND Journal of Economics 38: 60-84.

Kahneman, D., and A. Tversky. 1984. "Choices, Values, and Frames.” American Psychologist 39: 341 .

Kirman, A., 2011. "Learning in Agent-Based Models.” Eastern Economic Journal 37: 20-27.

LeBaron, B., and P. Winker. 2008. "Introduction to the Special Issue on Agent-Based Models for Economic Policy Advice." Journal of Economics and Statistics (Jahrbücher für

Nationalökonomie und Statistik) 228: 141-148.

Nordic Energy Regulators. 2014. Nordic Market Report 2014: Development in the Nordic Electricity Market (Technical Report). Accessed November

2015: http:/www.nordicenergyregulators.org/wp-content/uploads/2014/06/Nordic-MarketReport-2014.pdf.

Potomac Economics LTD. 2015. 2014 State of the Market Report for the ERCOT Wholesale Electricity Markets (Technical Report). Accessed November

2015: https://www.potomaceconomics.com/uploads/ercot documents/2014 ERCOT State of t he Market Report.pdf.

Praca, I., C. Ramos, Z. Vale, and M. Cordeiro. 2003. "MASCEM: A Multiagent System That Simulates Competitive Electricity Markets.” IEEE Intelligent Systems 18, 54-60.

Simon, H.A. 1955. "A Behavioral Model of Rational Choice.” The Quarterly Journal of Economics 69: 99-118.

Stoft, S. 2002. Power System Economics: Designing Markets for Electricity. New York, NY: IEEE Press \& Wiley-Interscience, John Wiley \& Sons, Inc.

Sun, J., and L. Tesfatsion. 2007. "Dynamic Testing of Wholesale Power Market Designs: An Open-Source Agent-Based Framework.” Computational Economics 30: 291-327.

Tesfatsion, L., and K.L. Judd. 2006. Handbook of Computational Economics: Agent-Based Computational Economics vol. 2. Amsterdam: Elsevier.

Twomey, P., R. Green, K. Neuhoff, and D. Newbery. 2006. “A Review of the Monitoring of Market Power: The Possible Roles of TSOs in Monitoring for Market Power Issues in Congested Transmission Systems." Working paper in economics. Cambrdige, United Kingdom: University of Cambridge.

Weidlich, A., and D. Veit. 2008. "Analyzing Interrelated Markets in the Electricity Sector: The Case of Wholesale Power Trading in Germany." In IEEE Power and Energy Society General 
Meeting Proceedings: Conversion and Delivery of Electrical Energy in the 21st Century, 1-8. Piscataway, NJ: Institute of Electrical and Electronics Engineers.

Weron, R., M. Bierbrauer, and S. Trück. 2003. Modeling Electricity Prices: Jump Diffusion and Regime Switching (Technical Report). Wroclaw, Poland: Wroclaw University of Technology, Hugo Steinhaus Center, HSC Research Reports. 